\title{
Physiotherapy for stress urinary incontinence: a national survey
}

\author{
Jill Mantle, Eboo Versi
}

\begin{abstract}
Objective-To study the physiotherapeutic treatment of urinary stress incontinence in England.

Design-Postal questionnaire survey.

Setting-All 192 English district health authorities.

Subjects-One physiotherapist from each district who was primarily concerned with urinary incontinence. A consensus view was requested.

Main outcome measures-Responses to questionnaire and analysis of a visual analogue scale to indicate effectiveness.

Results - There was a $98 \%$ response rate. Treatment was often by senior physiotherapists (108 senior I grade or above) who, in 117 districts, claimed to have made a specialty of treating the condition. Gynaecologists and obstetricians were far more likely to refer patients than any other agency (147 respondents said that they were the commonest source of referral). One hundred and fifty four respondents stated that physiotherapy was usually used as the first line of treatment. Pelvic floor exercises and interferential treatment were most commonly used (by 178 and 144 respondents respectively) and thought to be the most effective, especially in combination, though various techniques were used in applying them. Positive motivation (108), recent onset of symptoms (55), and youth (40) were viewed optimistically, and obesity (60), previous surgery (59), prolapse (42), and a chronic cough (36) were considered to be bad prognostic features. The number of patients treated varied greatly (range 10-360) between districts and was poorly correlated with catchment size (correlation coefficient $0 \cdot 3$ ).

Conclusions-As physiotherapists are treating considerable numbers of patients with stress incontinence research is urgently needed to produce efficacy data to enable rationalisation of resources to cater for the whole population.
\end{abstract}

\section{Introduction}

The treatment offered to women with uncomplicated stress incontinence depends largely on the preferences of the agencies consulted, the skills and persuasions of the professionals, and the severity of the condition. Naturally, surgeons often favour surgery, but this method has risks.' There is, therefore, a place for conservative management, and physiotherapy has long been an option, particularly for women who have not completed their childbearing and for those with mild symptoms.

Physiotherapeutic treatment has consisted of training the patient to recognise, perform, and practise voluntary contraction of the muscles of the pelvic floor. ${ }^{2}$ The purpose is to build up the muscle strength and bulk to support urethral closure, especially in stress situations. Electrostimulation has been used to help patients to identify levator ani contractions. Other physiotherapeutic means of encouraging pelvic floor contractions include perineometers, ${ }^{3}$ vaginal cones, ${ }^{45}$ and general exercises.

The physiotherapist has to decide exactly how to treat a patient with stress incontinence, but there is little published data on the efficacy of different types of physiotherapy. Nor is it certain what changes when a woman's stress incontinence improves after such treatment. . $^{611}$

We studied how physiotherapists most commonly treat uncomplicated stress urinary incontinence in women with the aim of designing future efficacy studies.

\section{Methods}

In February 1989 the district or senior superintendent physiotherapist in each of the 192 health authorities in England was sent an eight page detailed questionnaire. Only one of the authors (JM) was named in the covering letter, and the respondents were not aware that there was a gynaecological interest in this study. The questionnaire had been designed to survey the physiotherapy service currently available to the patients referred with uncomplicated stress incontinence. We asked that the physiotherapist in the district who most commonly treated patients with stress incontinence should fill in the questionnaire and that she should make an effort to represent the local consensus. The questions were designed to elicit the following information: (a) the seniority and qualifications of physiotherapy staff commonly treating such patients; $(b)$ the agency and reason for referral ranked in order (with equal rankings allowed); (c) the modalities available and the two most commonly selected; (d) details of treatment techniques; (e) the physiotherapists' perception of the efficacy of each available modality as expressed on a visual analogue scale; $(f)$ the physiotherapists' opinion of the prognostic features in a patient at presentation; $(g)$ the current annual caseload.

At the end of March 1989 a second questionnaire was sent out to the authorities that had not responded. Three months later the districts still outstanding were contacted again. Five months after the initial questionnaire was sent out the survey was closed.

\section{Results}

Within two months an $84 \%$ (161) response had been obtained. After a second posting to non-respondents only three of the 192 district authorities failed to send in a questionnaire, giving a final response rate of $98 \%$.

\section{PERSONNEL}

In 108 areas the physiotherapists usually treating stress incontinence were of senior I grade or above, and in 117 areas therapists had made a specialty of treating stress incontinence. In only 88 districts, however, had staff completed relevant postregistration training validated by the Chartered Society of Physiotherapy, and only nine districts had a physiotherapist member of the International Continence Society.

\section{REFERRAL PATTERNS}

Referring agents-Table I shows that obstetricians and gynaecologists were ranked as the top referral agency. Three respondents did not complete this question.

Reasons for referral-Table II shows physiotherapists'
Mr Versi.

BMF 1991;302:753-5 
Faradism uses low frequency alternating current Ranking given by No of respondents Invers

\begin{tabular}{|c|c|c|c|c|c|}
\hline \multirow[b]{2}{*}{ Source } & & \multirow{2}{*}{$\begin{array}{r}\text { mean o } \\
\text { ranks }\end{array}$} \\
\hline & 1 & 2 & 3 & 4 & \\
\hline Obstetricians and gynaecologists & 157. & 20 & 6 & 3 & 0.91 \\
\hline General practitioners & 24 & 84 & 40 & 38 & $0 \cdot 48$ \\
\hline Urologists & 14 & 60 & 55 & 57 & $0 \cdot 41$ \\
\hline Other & 5 & 10 & 34 & 136 & $0 \cdot 30$ \\
\hline
\end{tabular}

TABLE II - Reasons for referral to physiotherapist

\begin{tabular}{|c|c|c|c|c|c|c|}
\hline \multirow[b]{2}{*}{ Reason } & \multicolumn{5}{|c|}{ Ranking given by No of respondents } & \multirow{2}{*}{$\begin{array}{l}\text { Inverse } \\
\text { mean of } \\
\text { ranks }\end{array}$} \\
\hline & 1 & 2 & 3 & 4 & 5 & \\
\hline First line of treatment & 154 & 12 & 7 & 2 & 8 & 0.90 \\
\hline Awaiting surgery & 12 & 77 & 37 & 22 & 30 & $0 \cdot 42$ \\
\hline Unsuitable for surgery & 11 & 37 & 58 & 44 & 29 & $0 \cdot 38$ \\
\hline Failed surgery & 13 & 36 & 42 & 34 & 50 & $0 \cdot 36$ \\
\hline Declined surgery & 4 & 27 & 40 & 40 & 60 & $0 \cdot 31$ \\
\hline
\end{tabular}

TABLE III - Techniques used by respondents to confirm pelvic floor contraction

\begin{tabular}{lr}
\hline Technique & \\
\hline $\begin{array}{l}\text { Ask if patient can stop or } \\
\text { start midstream }\end{array}$ & 178 \\
$\begin{array}{l}\text { Vaginal examination by } \\
\text { patient }\end{array}$ & 155 \\
$\begin{array}{l}\text { Vaginal examination by } \\
\text { physiotherapist }\end{array}$ & 107 \\
Observation of the & 86 \\
$\quad$ perineum & 47 \\
Use a perineometer & 13 \\
Ask partner at intercourse & 0 \\
Do nothing & 16 \\
Other & \\
\hline
\end{tabular}

impressions of the commonest reasons for referral listed in order of preference. The inverse mean rank score for physiotherapy as the first line of treatment was 0.90 with surgically related indications having similar scores of about $0 \cdot 37$. This suggests that the respondents thought that in most cases patients were referred for physiotherapy as the first line of treatment. Six respondents did not complete this question.

\section{DETAILED TREATMENT TECHNIQUES}

Pelvic floor contractions - Table III shows the number of responding districts in which physiotherapists were using various measures to ensure that the patient was able voluntarily to contract the correct muscles. All respondents answered this question. Other means offered included vaginal cones, tension on withdrawal of tampon or Foley catheter, palpation of perineum, observation of the perineum by the patient using a mirror, and seeing a tilt on inserting a vaginal electrode. When teaching pelvic floor contractions 185 of the respondents explained the anatomy and the nature of the condition. This took an average of 22 minutes (range 5-60). Instruction in pelvic floor contraction was available in all districts and the mean time taken to teach this to a new patient was 20 minutes (range 5-180). One hundred and thirty of the respondents encouraged women to hold a contraction for four or five seconds if possible (range 1-30) and to perform four or five such contractions (range 1-50) at each practice session. Seventeen and 24 respondents respectively did not answer these two sections. In 111 districts patients were also taught quicker shorter contractions. In 136 districts women were advised to practise at least every hour. Overall, 169 districts responded to this question.

General exercise-Overall, 113 respondents considered that general exercise was available as a modality. Where actual exercises were described these consisted mainly of trunk exercises performed lying down often combined with voluntary pelvic floor contractions.

Interferential treatment uses the interaction of two medium frequency currents and was available in 176 districts. The commonest interferential machines for the treatment of stress incontinence in NHS departments were those manufactured by Bosche (59), Nomeq (57), and Medici (32). Table IV shows that four electrodes were used more commonly than two and that the $4000 \mathrm{~Hz}$ carrier wave was the most usual. Considerable variation was found in the frequency sweeps used and 62 different permutations were offered. The mean duration of the first treatment, which is usually shorter than subsequent ones, was 13 minutes (range 5-45). The mean number of treatments a week was three (range 1-5), and the number of treatments in a course was 11 (range 1-20). treatments in various modulations capable of producing a contraction of the pelvic floor musculature. This was available to the physiotherapist in 103 areas. No particular machine was favoured but an indifferent electrode over the sacrum or lumbar region (59) and an active vaginal electrode (55) or button or pad electrode on the perineum (32) was preferred in the 87 health districts responding to this section. This type of treatment was used to educate muscle awareness in 85 of these districts and to improve muscle strength in 31 .

Interrupted direct current was used for muscle stimulation in only two health districts. It produces more sensory stimulation than either of the other types of electrical current so is less acceptable to patients.

Perineometer-Only 50 district health authorities had a perineometer, and in most this was the Bourne perineometer (Doncast, Caterham, Surrey). Only in seven of these areas was it possible for patients to take a machine home. Forty five respondents completed the section on the reasons for its use. Nearly all (44) thought that it was an aid to patient motivation, but it was also used to monitor treatment in 38 and to determine pretreatment muscle strength in 33 .

Cones were available in 31 districts, although a further 10 hoped to have them in use shortly. Respondents indicated that the usual time taken to teach a patient to use cones was 15 minutes (range 3-30). Most physiotherapists were using the manufacturer's recommendations (Femina) for determining the baseline cone and subsequent practice. Patients were first reviewed on average after 13 days (range 1-60) and then reviewed five times (range 3-6). The mean time taken for these reviews was 19 minutes (range 5-60).

Other possible treatments-Table V shows the most commonly offered other treatments. The Foley catheter balloon is inflated, inserted into the vagina, and used to provide a sensory input to facilitate pelvic floor contractions.

\section{AVAILABILITY AND EFFICACY}

Table VI shows the availability of treatments in the responding health districts together with the perceived efficacy of each in treating uncomplicated stress in-

TABLE IV-Use of electrode, carrier wave, and frequency sweep among respondents

\begin{tabular}{lr}
\hline & $\begin{array}{c}\text { No of } \\
\text { respondents }\end{array}$ \\
\hline Electrodes: & \\
4 Electrodes & 106 \\
4 or 2 electrodes & 24 \\
2 Electrodes & 40 \\
Do not use it or no response & 19 \\
Carrier wave: & \\
$4000 \mathrm{~Hz}$ & 81 \\
$2000 \mathrm{~Hz}$ & 49 \\
4000 or $2000 \mathrm{~Hz}$ & 4 \\
Other & 3 \\
Do not use it or no response & 52 \\
Frequency sweep: & \\
$0-100 \mathrm{~Hz}$ & 43 \\
U-100 Hz and other & 30 \\
10-50 Hz & 39 \\
10-50 Hz and other & 27 \\
Other ranges & 27 \\
Do not use it or no response & 23 \\
\hline
\end{tabular}

TABLE V-Other treatments offered

\begin{tabular}{lc}
\hline Treatment & $\begin{array}{c}\text { No of } \\
\text { respondents }\end{array}$ \\
\hline Advice on diet or continence & 6 \\
Home battery stimulator $(10$ and $30 \mathrm{~Hz})$ & 5 \\
Foley catheter & 4 \\
Audio cassettees containing instruction or advice for use at & 3 \\
home & 2 \\
\hline Frequency volume charts & \\
\hline
\end{tabular}

.




\begin{tabular}{lcc}
\hline Modality & Availability & $\begin{array}{c}\text { Efficacy } \\
\%\end{array}$ \\
\hline Pelvic floor contractions & 189 & 74 \\
Interferential treatment & 176 & 63 \\
General exercises & 113 & 38 \\
Faradism & 103 & 45 \\
Perineometer & 50 & 57 \\
Vaginal cones & 31 & 59 \\
Interrupted direct current & 8 & 17 \\
\hline
\end{tabular}

continence as indicated on a $10 \mathrm{~cm}$ visual analogue scale. Pelvic floor contractions and interferential treatment were the top two in terms of availability, efficacy, and preference (pelvic floor exercises were preferred by 178 and interferential treatment by 144). Seventy five respondents thought that a combination of these two modalities was more effective than either treatment alone.

\section{PROGNOSTIC FEATURES}

In two open questions physiotherapists were asked their opinion on the features in the patient's history or condition that made them pessimistic or optimistic about improving stress incontinence with physiotherapy. These questions were answered by 149 and 140 of the respondents respectively. The common pessimistic features were lack of motivation (64), obesity (60), previous surgery (59), long duration of symptoms (57), concomitant prolapse (42), and chronic cough (36). On the optimistic side positive motivation (108), recent onset of symptoms (55), ability to contract the pelvic floor at presentation (42), and "young or postmenopausal" (40) were the most common features.

\section{CASELOAD}

Finally, respondents were asked to estimate the average number of women with stress incontinence treated in the health district by physiotherapeutic methods each year. The range varied widely from 10 to 360 , with 51 respondents giving no figure. When the caseload was compared with the size of the catchment area, however, there was a correlation coefficient of $0 \cdot 3 .^{12}$

\section{Discussion}

The exceptional response to this postal survey indicates that the findings, despite being subjective, are representative. This questionnaire was evidently regarded as being of high priority and relevant. We gained the overall impression that physiotherapists were a well trained, motivated, professional group, who were very interested in continence care.

Though physiotherapists consider that treating stress incontinence requires experience and maturity, 101 districts were without a physiotherapist with relevant postregistration training.

It was surprising to find obstetricians and gynaecologists as the chief referral agency, though possibly they are more aware of the potential of physiotherapy through contact in antenatal and postnatal care. It has been suggested that urologists are referred more complicated cases and that they send patients with simple stress incontinence to nurse continence advisers. We are currently investigating this possibility. General practitioners probably refer first to a consultant rather than directly to a physiotherapist. In the light of the forthcoming changes in the NHS this may be reversed.

That "the first line of treatment" was seen by therapists to be the the prime reason for referral was unexpected. Women awaiting surgery are sent for physiotherapy in some centres. The benefit of this is unproved and so may be a waste of resources. The fact that surgically related indications scored so poorly was surprising. In particular we would have expected the indication of "declined surgery" to have been more prominent.

It has been claimed that the results of surgery are better than those of physiotherapy. ${ }^{13}$ Though physiotherapy is unlikely to cure, considerable improvement can none the less be achieved with very little risk. It is generally agreed that patients who are most likely to benefit from physiotherapy - for example, thin, young, premenopausal women - are also likely to do best from surgery. Though our survey would to some extent support this, there is an urgent need for reliable criteria to be established to determine cost effective management for stress incontinence.

There was a wide variety of proferred techniques for treatment, particularly for interferential treatment, implying that there is little consensus. This could explain the observed variable success of physiotherapy. Possible reasons for this variation are the type of electrical equipment used and therefore the modulations available and the lack of efficacy data. This deficiency is perpetuated even with recently introduced techniques, such as vaginal cones. Despite the fact that they were introduced only in 1985 , by $198916 \%$ of districts had this facility yet there has been no objective evidence of their effectiveness. ${ }^{5}$ Thus the rationale for most techniques is largely apocryphal and so well organised research is needed.

Pelvic floor exercises and interferential treatment, the two types of treatment most favoured by physiotherapists, were also the most commonly available and considered the most effective. Twelve respondents, however, indicated that insufficient resources-for example, staff, interferential machines, etc-prevented the effective delivery of services.

Given that the questions on prognostic features were open, the response highlighting motivation was massive, indicating its importance. These features can now be tested formally; a reproducible means of evaluating them to help patient selection would greatly enhance the cost effectiveness of the treatment. ${ }^{14}$

We thank all the respondents for answering the questionnaire. This study was not funded and so we are grateful to Professor Grudzinskas, department of obstetrics and gynaecology, the Royal London Hospital, for allowing us the use of departmental facilities.

1 Stanton SL. Surgical management of urethral sphincter incompetence. In: Norton PA, ed. Clinical obstetrics and gynaecology. Philadelphia: Lippincott, 1990:346-57.

2 Harrison SM. Urinary incontinence of non-neurogenic origin. Physiotherapy 1973;59:363-5.

Kegel AH. The non-surgical treatment of genital relaxation. Annals Western Medicine and Surgery 1948:2:213-6.

4 Peattie AB, Plevnik S, Stanton SL. Vaginal cones: a conservative method of Weating, Pevik S, Stany

5 Versi E, Mantle J. The use of vaginal cones in the management of genuine stress incontinence. Br $\mathcal{F}$ Obstet Gynaecol 1989;96:752-3.

6 Stoddart GD. Research project into the effect of pelvic floor exercises on genuine stress incontinence. Physiotherapy 1983;69:143-4.

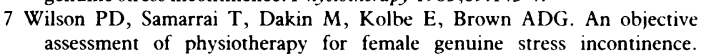
Brf Obstet Gynaecol 1984;94:575-82.

8 Klarskov P, Belring D, Bischoff N, et al. Pelvic floor exercises versus surgery for female urinary stress incontinence. Urol Int 1986;41:129-32.

9 Tehon D, Adams C, Varner RE, Denton B. Pelvic floor musculature exercises in treatment of anatomical urinary stress incontinence. Phys Ther 1988;68:652-5.

10 Switzer D, Hendriks O. Interferential therapy for the treatment of stress and urge incontinence. Ir Med f 1988;81:30-1.

11 Bo K, Hagen R, Jorgensen J, Kvarstein B, Larsen S. The effect of two different pelvic floor muscle exercise programs in treatment of urinary stress incontinence in women. Neurology and Urodynamics 1989;8:355-6.

12 Office of Population Censuses and Surveys. Key population and vital statistics. Office of Population Censuses and Surveys. Key population and vital slat
London: HMSO, 1987:74-85. (Series VS 1987 No 14, PP1, No 10.)

13 Tapp AJS, Hills B, Cardozo LD. Randomized study comparing pelvic floor physiotherapy with the Burch colposuspension. Neurology and Urodynamics physiotherapy
1989;8:356-7.

14 Tapp AJS, Cardozo L, Hills B, Barnick C. Who benefits from physiotherapy? Neurology and Urodynamics 1988;7:259-61.

(Accepted 18 January 1991) 